\title{
PENGARUH INISIASI MENYUSU DINI TERHADAP KEJADIAN HIPOTERMIA PADA BAYI BARU LAHIR DI PUSKESMAS SUMBERSARI KABUPATEN JEMBER
}

\author{
Hilmy Dzakiyyah Wildan', Pertiwi Febriana ${ }^{2}$
}

Fakultas Kedokteran Universitas Muhammadiyah Malang, J1. Bendungan Sutami No. 188-A, Kota Malang, 65145, Indonesia, 0341-552443 / 0341-551149

Email: hilmy.dzakiyyah@gmail.com

\begin{abstract}
ABSTRAK
PENGARUH INISIASI MENYUSU DINI TERHADAP KEJADIAN HIPOTERMIA PADA BAYI BARU LAHIR DI PUSKESMAS SUMBERSARI KABUPATEN JEMBER. Latar Belakang: Data stastistik WHO menyatakan bahwa Neonatal Mortality Rate Indonesia pada tahun 2010 adalah 17 per 1000 kelahiran hidup. Menurut RISKESDAS tahun 2007, prevalensi kematian neonatus pada bayi usia 0-6 hari di Indonesia yang disebabkan oleh hipotermia adalah sebesar 7\%. Inisiasi menyusu dini dapat menurunkan angka kematian bayi karena hipotermia.

Tujuan Penelitian: Untuk mengetahui pengaruh inisiasi menyusu dini terhadap kejadian hipotermia pada bayi baru lahir di Puskesmas Sumbersari Kabupaten Jember.

Metode Penelitian: Quasi experiment dengan pretest dan posttest. Teknik pengambilan sampel adalah total sampling. Sampel yang digunakan adalah bayi baru lahir yang mendapatkan inisiasi menyusu dini di wilayah kerja Puskesmas Sumbersari Kabupaten Jember pada tanggal 1 - 27 Februari 2014. Jumlah sampel yang didapatkan adalah 31 sampel, kemudian sampel diukur suhu aksila sebelum dan sesudah dilakukan inisiasi menyusu dini menggunakan termometer digital.

Hasil penelitian: Analisis data yang digunakan adalah Paired T-Test dan didapatkan hasil yang signifikan (sig. 0,000) dengan rata-rata suhu sebelum IMD yaitu $36.539^{\circ} \mathrm{C}$ dan sesudah IMD yaitu $37,255^{\circ} \mathrm{C}$.

Kesimpulan: $\quad$ Ada pengaruh inisiasi menyusu dini terhadap kejadian hipotermia pada bayi baru lahir di Puskesmas Sumbersari Kabupaten Jember yaitu menurunkan resiko kejadian hipotermia pada bayi baru lahir.
\end{abstract}

\begin{abstract}
THE EFFECT EARLY INITIATION OF BREASTFEEDING IN HYPOTHERMIA INCIDENCE OF THE NEWBORN AT PUSKESMAS SUMBERSARI KABUPATEN JEMBER. Background: Data statistic of WHO states that Neonatal Mortality Rate of Indonesia in 2010 is 17 per 1000 live births. According to RISKESDAS in 2007, prevalence of neonatus death, age 0-6 days, in Indonesia caused by bypothermia is 7\%. Early initiation of breastfeeding can decrease the number of infant death that is caused by hypothermia.

Objective: To understand the effect early initiation of breastfeeding in bypothermia incidence of the newborn at Puskesmas Sumbersari Kabupaten Jember.

Method: Quasi experiment with pretest and posttest. The technique sampling is total sampling. The sample used is newborn who get early initiation of breastfeeding in working area of Puskesmas Sumbersari Kabupaten Jember on February $1^{\text {st }}$ until $27^{\text {th }}$, 2014. The number of sample is 31 samples, and then the samples are measured of axilla temperature before and after early initiation of breastfeeding by digital thermometer.

Result: $\quad$ The data analysis used is Paired T-Test. It has significant result (sig. 0,000) with mean of temperature before early initiation of breastfeeding is $36.539^{\circ} \mathrm{C}$, and after early initiation of breastfeeding is $37,255^{\circ} \mathrm{C}$.

Conclusion: Early initiation of breastfeeding has effect in hypothermia incidence of the newborn at Puskesmas Sumbersari Kabupaten Jember which can decrease hypothermia risk of the newborn.
\end{abstract}

Key word: Early initiation of breastfeeding, Hypothermia, Newborn

\section{PENDAHULUAN}

Hingga saat ini angka kematian neonatus di Indonesia masih cukup tinggi. Menurut World Health Organization (WHO), data statistik menyatakan bahwa Neonatal Mortality Rate Indonesia pada tahun 2010 adalah 17 per 1000 kelahiran (WHO, 2012). Menurut Riset Kesehatan Dasar
(RISKESDAS) tahun 2007, prevalensi kematian neonatus pada bayi usia 0-6 hari di Indonesia yang disebabkan oleh hipotermia adalah sebesar 7\% (Depkes RI, 2008).

Hipotermia adalah suatu keadaan apabila suhu tubuh di bawah $36,5^{\circ} \mathrm{C}$. Hipotermia pada bayi baru lahir disebabkan belum sempurnanya pengaturan suhu tubuh bayi, maupun 
pengetahuan yang kurang tentang pengelolaan bayi baru lahir yang benar. Hipotermia merupakan salah satu penyebab utama tingginya angka morbiditas dan mortalitas bayi baru lahir (Puspita, 2007). Jika suhu tubuh turun di bawah $85^{\circ} \mathrm{F}$, kemampuan hipotalamus untuk mengatur suhu akan hilang. Bila tidak ditangani dengan segera, orang yang terpajan dingin yang ekstrim selama hampir 20-30 menit biasanya akan meninggal karena henti jantung atau fibrilasi jantung (Guyton, 2008).

Inisiasi Menyusu Dini (IMD) merupakan proses membiarkan bayi menyusu sendiri setelah kelahiran. Bayi diletakkan di dada ibunya dan bayi itu sendiri dengan segala upayanya mencari puting untuk segera menyusui (Yuliarti, 2010).

Inisiasi menyusu dini merupakan program yang sedang gencar dianjurkan oleh pemerintah. Dari hasil penelitian dalam dan luar negeri, ternyata inisiasi menyusu dini dapat mensukseskan pemberian Air Susu Ibu (ASI) eksklusif. Lebih dari itu, terlihat hasil yang nyata, yaitu menyelamatkan bayi. Manfaat inisiasi menyusu dini untuk bayi salah satunya adalah menurunkan Angka Kematian Bayi (AKB) yang disebabkan oleh hipotermia serta dapat menghangatkan bayi melalui dada ibu dengan suhu yang tepat. Menurut penelitian Bergman, kulit ibu berfungsi sebagai inkubator, karena kulit ibu merupakan thermoregulator bagi bayi. Jika semua bayi di dunia segera setelah lahir diberi kesempatan menyusu sendiri dengan membiarkan kontak kulit ibu ke kulit bayi setidaknya selama satu jam, maka satu juta nyawa bayi dapat diselamatkan (Roesli, 2008).

Data yang didapatkan dari Puskesmas Sumbersari Kabupaten Jember pada tahun 2013 tercatat 1.099 kelahiran bayi dan yang mendapatkan inisiasi menyusu dini sebesar 95,18\% (Dinkes Jember, 2014). Pada bulan SeptemberOktober 2013, terdapat kejadian hipotermia pada bayi baru lahir di Puskesmas Sumbersari Kabupaten Jember yaitu hipotermia ringan $35,29 \%$, hipotermia sedang $14,71 \%$, dan hipotermia berat 8,82\% (Maya, 2013). Oleh karena itu, peneliti tertarik untuk melakukan penelitian tentang pengaruh inisiasi menyusu dini terhadap kejadian hipotermia di Puskesmas Sumbersari Kabupaten Jember.

\section{METODE}

Jenis penelitian yang digunakan adalah quasi experiment dengan pretest dan posttest. Penelitian ini dilakukan pengamatan pada sebelum dan sesudah perlakuan, tetapi dalam penelitian ini tidak ada kelompok kontrol. Penelitian ini dilakukan di wilayah kerja Puskesmas Sumbersari Kabupaten Jember pada tanggal 1-27 Februari 2014.

Pengambilan sampel menggunakan teknik total sampling yaitu seluruh bayi baru lahir yang lahir pada kurun waktu tersebut dan dilakukan inisiasi menyusu dini di Puskesmas Sumbersari Kabupaten Jember, dengan karakteristik eksklusinya adalah bayi baru lahir yang lahir dengan asfiksia, dengan tindakan (vakum, operasi caesar), lahir kurang bulan (prematur), kelainan bawaan, berat badan $<2.500$ gram, dan ibu melahirkan dengan retracted nipple.

Setelah ditentukan sampelnya, dilakukan pengukuran suhu pertama sebelum inisiasi menyusu dini (saat lahir). Kemudian dilakukan inisiasi menyusu dini kurang lebih 1 jam sesuai dengan check list yang ada. Selanjutnya dilakukan pengukuran suhu kedua sesudah inisiasi menyusu dini. Pengukuran ini dilakukan menggunakan termometer aksila digital. Data tersebut dicatat di lembar observasi kemudian dianalisis dengan uji komparasi dua sampel dengan sampel data berbentuk skala interval yaitu membandingkan suhu bayi baru lahir sebelum dan sesudah dilakukan inisiasi menyusu dini. Uji statistik yang digunakan adalah Paired $T$ Test dengan SPSS.

\section{HASIL DAN PEMBAHASAN}

Karakteristik pada BBL yang dilakukan inisiasi menyusu dini tercantum dalam tabel 1. Karakteristik yang diukur meliputi berat badan lahir (gram) dan umur kehamilan ibu (minggu)

Tabel 1. Karakteristik dan Distribusi BBL yang Dilakukakan Inisiasi Menyusu Dini

\begin{tabular}{ccc}
\hline Karakteristik & $\begin{array}{c}\text { Frekuensi } \\
(\mathrm{n}=31)\end{array}$ & $\begin{array}{c}\text { Persentase } \\
(\%)\end{array}$ \\
\hline Berat badan lahir & & \\
$2.600-2.900$ gram & 8 & 26 \\
$3.000-3.300$ gram & 18 & 58 \\
$3.400-3.700$ gram & 5 & 16 \\
Umur kehamilan ibu & & \\
$37-<39$ minggu & 5 & 16 \\
$39-<41$ minggu & 22 & 71 \\
$\geq 41$ minggu & 4 & 13 \\
\hline
\end{tabular}

Tabel 2. Distribusi Suhu BBL dan Kejadian Hipotermia Sebelum dan Sesudah Dilakukan Inisiasi Menyusu Dini

\begin{tabular}{ccccc}
\hline \multirow{2}{*}{ Distribusi } & \multicolumn{2}{c}{ Sebelum IMD } & \multicolumn{2}{c}{ Sesudah IMD } \\
\cline { 2 - 5 } & $\begin{array}{c}\text { Frekuensi } \\
(\mathrm{n}=31)\end{array}$ & Persentase $(\%)$ & $\begin{array}{c}\text { Frekuensi } \\
(\mathrm{n}=31)\end{array}$ & Persentase (\%) \\
\hline Suhu BBL & 8 & 26 & 0 & 0 \\
$36,0-36,4^{\circ} \mathrm{C}$ & 22 & 71 & 5 & 16 \\
$36,5-36,9^{\circ} \mathrm{C}$ & 1 & 3 & 24 & 78 \\
$37,0-37,5^{\circ} \mathrm{C}$ & 0 & 0 & 2 & 6 \\
$>37,5^{\circ} \mathrm{C}$ & & & & \\
Kejadian & 8 & 26 & 0 & 0 \\
Hipotermia & 23 & 74 & 29 & 94 \\
Suhu Normal & 0 & 0 & 2 & 6 \\
Hipertermia & & &
\end{tabular}


Tabel 3. Analisis Deskriptif

\begin{tabular}{lcc}
\hline \multicolumn{1}{c}{ Deskriptif } & Rata-rata $(\mathrm{n}=31)$ & Standar Deviasi \\
\hline Suhu sebelum IMD & $36,539^{\circ} \mathrm{C}$ & 0,2512 \\
Suhu sesudah IMD & $37,255^{\circ} \mathrm{C}$ & 0,2461 \\
Kenaikan suhu & $0,716^{\circ} \mathrm{C}$ & 0,2296 \\
\hline
\end{tabular}

Tabel 4. Hasil Analisis Paired T-Test dan Korelasi

\begin{tabular}{cccc}
\hline Hasil Analisis & Nilai & Signifikansi & Keterangan \\
\hline $\mathrm{T}$ & $-17,364$ & 0,000 & $\mathrm{H}_{\mathrm{o}}$ ditolak \\
Korelasi & 0,574 & 0,001 & $\mathrm{H}_{\mathrm{o}}$ ditolak \\
\hline
\end{tabular}

Berdasarkan data tabel 2, diketahui bahwa sebelum dilakukan inisiasi menyusu dini terdapat 8 kejadian hipotermia (26\%) dan 23 kejadian suhu normal (74\%). Sesudah dilakukan inisiasi menyusu dini diketahui bahwa tidak ada kejadian hipotermia, 29 kejadian suhu normal (94\%), dan 2 kejadian hipertermia (6\%). Hal ini menunjukkan bahwa dengan inisiasi menyusu dini, kejadian hipotermia banyak berkurang. Pada tabel 3, dapat diketahui kenaikan suhu yang disebabkan oleh tindakan inisiasi menyusu dini memiliki rata-rata sebesar $0,716^{\circ} \mathrm{C}$.

Pada hasil analisis Paired T-Test, didapatkan bahwa inisiasi menyusu dini berpengaruh terhadap kejadian hipotermia pada bayi baru lahir dengan signifikansi 0,000. Hal ini disebabkan karena inisiasi menyusu dini merupakan permulaan menyusu dini, dimana terjadi kontak kulit antara ibu dan bayi (Roesli, 2008). Kontak kulit yang disebut juga sebagai Skin-to-Skin Contact (SSC) ini dapat efektif sebagai penghangat untuk mencegah kehilangan panas pada bayi baru lahir yang normal dan sehat (Christidis, 2003).

Kontak kulit ini, melalui rangsangan sensorik seperti sentuhan, kehangatan, dan bau, dapat menjadi rangsangan vagal yang kuat. Rangsangan ini memiliki salah satu efek yaitu pengeluaran hormon oksitosin maternal (Winberg, 2005). Stimulus isapan pada puting susu juga menimbulkan sinyal yang dijalarkan melalui saraf sensorik ke neuron oksitosin yang ada di dalam nucleus paraventrikuler dan supraoptik di hipotalamus yang menyebabkan timbulnya pelepasan oksitosin oleh kelenjar hipofisis posterior (Guyton, 2008). Oksitosin dapat menyebabkan peningkatan suhu pada payudara ibu, sehingga dapat pula untuk menghangatkan bayi (Riordan, 2010).

Menurut penelitian Bystrova tahun 2007, terjadi kenaikan suhu payudara pada ibu melahirkan yang melakukan kontak kulit dengan bayi selama 30 - 120 menit yaitu sebesar $0,60^{\circ} \mathrm{C}$. Suhu maternal ibu berhubungan dengan suhu aksila dan kaki bayi (Bystrova, 2007). Hal ini membuat suhu bayi baru lahir menjadi stabil. Bayi baru lahir yang mendapatkan kontak kulit dengan ibu sejak dini memiliki rata-rata kenaikan suhu $0,7^{\circ} \mathrm{C}$ (Marin, 2010).

Pada penelitian ini, suhu bayi baru lahir setelah inisiasi menyusu dini memiliki rata-rata sebesar $37,255^{\circ} \mathrm{C}$. Hal tersebut sejalan dengan penelitian Chiu tahun 2005. Selama terjadi kontak kulit ibu dan bayi, kebanyakan bayi akan mencapai dan mempertahankan suhu di antara $36,5^{\circ}-$ $37,6^{\circ} \mathrm{C}$, yang merupakan thermoneutral range. Hal ini terjadi karena ibu memiliki kemampuan untuk mengatur suhu bayi selama kontak kulit ibu dan bayi (Chiu, 2005)
Dari hasil penelitian ini, ditemukan 8 kejadian hipotermia (26\%) dan 23 kejadian suhu normal (74\%) sebelum dilakukan inisiasi menyusu dini serta tidak ada kejadian hipotermia $(0 \%)$ dan 29 kejadian suhu normal (94\%) setelah inisiasi menyusu dini. Hal ini sejalan dengan penelitian Nimbalkar tahun 2014 yaitu 4\% dari kelompok SSC/kontak kulit mengalami hipotermia, sedangkan pada kelompok kontrol (tidak dilakukan SSC/kontak kulit) sebanyak $16 \%$ bayi baru lahir yang mengalami hipotermia pada 48 jam pertama, sehingga dapat disimpulkan bahwa kontak kulit ibu dan bayi yang dilakukan sejak dini dapat mengurangi insiden hipotermia pada bayi cukup bulan maupun prematur akhir (Nimbalkar, 2014).

Ketidakstabilan suhu pada bayi baru lahir dipengaruhi salah satunya oleh berat badan lahir bayi dan umur gestasi saat bayi dilahirkan. Bayi kurang bulan dan bayi berat badan lahir rendah memiliki resiko ketidakstabilan suhu tubuh. Hal tersebut dikarenakan oleh kurangnya lemak subkutan, rasio luas permukaan terhadap berat badan yang besar, dan produksi panas yang berkurang akibat lemak coklat yang tidak memadai serta ketidakmampuan untuk menggigil (Damanik, 2010). Padahal mekanisme utama pada bayi baru lahir untuk mempertahankan termoregulasi adalah dengan cara non-shivering termoregulation, yaitu mekanisme yang dipengaruhi oleh sistem saraf simpatis untuk menstimulasi proses metabolik dengan melakukan oksidasi terhadap jaringan lemak coklat. Peningkatan metabolisme jaringan lemak coklat akan meningkatkan produksi panas dari dalam tubuh (Yunanto, 2010).

Hal tersebut sejalan dengan penelitian Rodrigo tahun 2014. Hasil penelitiannya menyatakan bahwa bayi baru lahir dengan berat badan lahir 1.137 $\pm 257,6$ gram dan umur gestasi $29,5 \pm 2,0$ minggu memiliki suhu rata-rata $35,8 \pm 0,6^{\circ} \mathrm{C}$. Hal tersebut menunjukkan bahwa bayi dengan berat badan lahir rendah dan prematur memiliki resiko tinggi terjadinya hipotermia (Rodrigo, 2014). Pada penelitian oleh Mullany tahun 2010 juga disebutkan bahwa berat badan lahir merupakan faktor resiko hipotermia. Rasio prevalensi hipotermia pada bayi baru lahir yang memiliki berat lahir < 2.000 gram lebih tinggi daripada bayi dengan berat lahir normal ( $>2.500$ gram). Setiap pengurangan berat badan lahir sebanyak 100 gram, resiko hipotermia akan meningkat $7,4 \%$ pada bayi dengan berat lahir 2.500-3.000 gram, 13,5\% pada bayi dengan berat lahir 2.000-2.500 gram dan 31,3\% pada bayi dengan berat lahir < 2.000 gram (Mullany, 2010).

Pada penelitian ini, pengukuran yang dilakukan adalah pengukuran suhu aksila. Hal ini disebabkan karena 
pengukuran suhu aksila ini lebih mudah, sederhana, dan aman (Yunanto, 2010). Selain itu, pada penelitian ini dilakukan pengukuran suhu sebanyak 2 kali, yaitu sebelum dan sesudah inisiasi menyusu dini, sehingga tidak dapat dilakukan pengukuran suhu rektal. Hal ini disebabkan karena pengukuran suhu rektal tidak dilakukan sebagai prosedur pemeriksaan rutin kecuali pada bayi-bayi sakit, karena dapat menyebabkan anus imperforatus (Yunanto, 2010).

Keterbatasan pada penelitian ini adalah tidak terdapatnya kelompok kontrol, yaitu bayi baru lahir yang tidak dilakukan inisiasi menyusu dini. Hal tersebut dikarenakan sesuai anjuran dari WHO, inisiasi menyusu dini harus dilakukan pada setiap bayi baru lahir normal, sehingga setiap bayi baru lahir di Puskesmas Sumbersari Kabupaten Jember dilakukan inisiasi menyusu dini. Kelompok bayi baru lahir post operasi caesar dapat dijadikan kelompok kontrol. Akan tetapi, penelitian dengan kontrol ini perlu dilakukan di tempat pelayanan kesehatan strata 2 seperti rumah sakit.

Keterbatasan penelitian lainnya adalah tidak diukurnya suhu ruangan di ruang persalinan, karena tidak tersedia alat pengukur suhu ruangan. Suhu ruangan atau lingkungan ini merupakan salah satu faktor yang mempengaruhi termoregulasi pada bayi baru lahir sehingga dapat juga mempengaruhi insiden hipotermia.

Suhu tubuh diatur dengan mengimbangi produksi panas terhadap kehilangan panas. Bila pembentukan panas dalam tubuh lebih besar daripada kehilangan panas, maka suhu tubuh akan meningkat. Suhu lingkungan yang berlebihan juga bisa mengakibatkan peningkatan suhu pada bayi baru lahir. Sebaliknya, bila kehilangan panas dalam tubuh lebih besar dari pada laju pembentukan panas maka akan terjadi penurunan suhu (Yunanto, 2010). Seperti halnya pada penelitian yang dilakukan oleh Jia tahun 2013 yaitu bayi baru lahir yang dilahirkan di ruang persalinan dengan suhu ruangan $25,1 \pm 0,6^{\circ} \mathrm{C}$ memiliki insiden hipotermia (suhu di bawah $36,0^{\circ} \mathrm{C}$ ) lebih rendah daripada bayi baru lahir yang dilahirkan di ruang persalinan dengan suhu ruangan $22,5 \pm 0,6^{\circ} \mathrm{C}$ (Jia, 2013). Untuk itu, inisiasi menyusu dini sangat perlu dilakukan karena dapat mempertahankan suhu normal pada bayi baru lahir dan mencegah terjadinya hipotermia pada bayi baru lahir.

\section{SIMPULAN}

Inisiasi menyusu dini memiliki pengaruh terhadap kejadian hipotermia pada bayi baru lahir di Puskesmas Sumbersari Kabupaten Jember (sig. $=0,000$ ) yaitu menurunkan resiko kejadian hipotermia pada bayi baru lahir. Rata-rata suhu bayi baru lahir sebelum dilakukan inisiasi menyusu dini sebesar $36,539^{\circ} \mathrm{C}$, sedangkan rata-rata suhu bayi baru lahir sesudah dilakukan inisiasi menyusu dini adalah sebesar $37,255^{\circ} \mathrm{C}$. Rata-rata kenaikan suhu oleh karena tindakan inisiasi menyusu dini di Puskesmas Sumbersari Kabupaten Jember adalah sebesar $0,716^{\circ} \mathrm{C}$. Jumlah kejadian hipotermia pada bayi baru lahir di Puskesmas Sumbersari Kabupaten Jember sebelum dilakukan inisiasi menyusu dini terdapat 8 kejadian (26\%), sedangkan sesudah dilakukan inisiasi menyusu dini tidak ada kejadian hipotermia $(0 \%)$.

\section{DAFTAR PUSTAKA}

Bergman N, Moore ER, Anderson GC, et. al. 2012. Early Skin-to-skin Contact for Mothers and Their Healthy Newborn Infants. Cochrane Database of Systematic Reviews 2012, Issue 5. Art. No. : CD003519

Bystrova K, Matthiesen AS, Varonstov I, et. al. 2007. Maternal Axillary and Breast Temperature After Giving Birth: Effects of Delivery Ward Practices and Relation to Infant Temperature. Journal of Birth; 2007 December, 34(4) : 291-300

Chiu SH, Anderson GC, Burkhammer MD. 2005. Newborn Temperature During Skin-to-Skin Breastfeeding in Couples Breastfeeding Difficulties. Journal of Birth, 2005 June; 32(2) : 115-121

Christidis I, Zotter H, Rosegger H, et. al. 2003. Infrared Thermography in Newborns : The First Hour After Birth. Journal of Gynakol Geburtshilfliche Rundsch, 2003 January; 43(1) : 31-35

Dahlan, Muhamad Sopiyudin. 2009. Statistik untuk Kedokteran dan Kesehatan : Deskriptif, Bivariat, dan Multivariat Dilengkapi Aplikasi dengan Menggunakan SPSS Edisi 4. Jakarta : Salemba Medika. h.66-70, 157

Damanik, SM. 2010. Klasifikasi Bayi Menurut Berat Lahir dan Masa Gestasi. Dalam : Kosim MS, Yunanto A, Dewi R, dkk. (ed). Neonatologi. Jakarta : Badan Penerbit IDAI. h.11-13

Departemen Kesehatan Republik Indonesia. 2006. Metode Amenore Laktasi. Dalam: Saifuddin AB, Affandi B, Baharuddin M, dkk. (ed). Buku Panduan Praktis Pelayanan Kontrasepsi Edisi 2. Jakarta : Yayasan Bina Pustaka Sarwono Prawirohardjo. h.MK-1

Departemen Kesehatan Republik Indonesia. 2008. Riset Kesehatan Dasar (RISKESDAS) 2007 : Laporan Nasional 2007. Diakses tgl 26 Oktober 2012. Diunduh dari URL: http://terbitan.litbang.depkes.go.id/ penerbitan/index.php/blp/catalog/download/22/22/ 29-2

Dewi, Vivian Nanny Lia. 2010. Asuhan Neonatus Bayi dan Anak Balita. Jakarta : Salemba Medika. h.1-4

Dinas Kesehatan Kabupaten Jember. 2014. Data AKI, AKB, IMD Kabupaten Jember Tahun 2013.

Edmond KM, Zandoh C, Quigley MA, et. al. 2006. Delayed Breastfeeding Initiation Increases Risk of Neonatal Mortality. Journal of Pediatrics 117 : 380-386

Gowen CW. 2014. Kedokteran Fetal dan Neonatal. Dalam : Rundjan L, Roeslani R (ed). Nelson Ilmu Kesehatan Anak Esensial Edisi Keenam. Singapore: Elsevier. h.256257

Guyton AC, Hall JE. 2008. Hormon-Hormon Hipofisis dan Pengaturannya oleh Hipotalamus. Dalam : Rachman LY, Hartanto H, Novrianti A, dkk. (ed). Buku Ajar Fisiologi Kedokteran Edisi 11. Jakarta : EGC. h.976

Guyton AC, Hall JE. 2008. Kehamilan dan Laktasi. Dalam : Rachman LY, Hartanto H, Novrianti A, dkk. (ed). Buku Ajar Fisiologi Kedokteran Edisi 11. Jakarta : EGC. h.1094

Guyton AC, Hall JE. 2008. Suhu Tubuh, Pengaturan Suhu, dan Demam. Dalam : Rachman LY, Hartanto H, Novrianti A, dkk. (ed). Buku Ajar Fisiologi Kedokteran 
Edisi 11. Jakarta : EGC. h.947

Jia YS, Lin ZL, Lu YM, et. al. 2013. Effect of Delivery Room Temperature on The Admission Temperature of Premature Infants: A Randomized Controlled Trial. Journal of Perinatol, 2013 April; 33(4) : 264-267

Kementerian Kesehatan Republik Indonesia. 2010. Buku Saku Pelayanan Kesehatan Neonatal Esensial : Pedoman Teknis Pelayanan Kesehatan Dasar. Jakarta : Kementerian Kesehatan RI. h.7-12

Marin GMA, Liana MI, Lopez EA, et. al. 2010. Randomized Controlled Trial of Early Skin- to-Skin Contact: Effects on The Mother and The Newborn. Journal of Acta Paediatrica, 2010 November; 99(11) : 1630-1634

Maya, Primadonna Dian. 2013. Gambaran Kejadian Hipotermia Bayi Baru Lahir (BBL) dengan Persalinan Spontan di Bidan Praktik Swasta Wilayah Kerja Puskesmas Sumbersari Kabupaten Jember tahun 2013. Skripsi Politeknik Kesehatan Kemenkes Malang Program Studi Kebidanan Jember

Mullany LC, Katz J, Khatry SK, et. al. 2010. Neonatal Hypothermia and Associated Risk Factors Among Newborns of Southern Nepal. Journal of BMC Med, 2010 July; 8 : 43

Nimbalkar SM, Patel VK, Patel DV, et.al. 2014. Effect of Early Skin-to-Skin Contact Following Normal Delivery on Incidence of Hypothermia in Neonates More Than $1800 \mathrm{~g}$ : Randomized Control Trial. Journal of Perinatol, 2014 February : 20.

Novita L, Gurnida DA, Garna H. 2008. Perbandingan Fungsi Kognitif Bayi Usia 6 bulan yang Mendapat dan Tidak Mendapat ASI Ekslusif. Jurnal Sari Pediatri Vol. 9, No.6, April 2008 : 429-434

Puspita IR, Suradi R, Munasir Z. 2007. Insiden dan Faktor Risiko Hipotermia Akibat Memandikan pada Bayi Baru Lahir. Jurnal Sari Pediatri Vol. 8, No. 4, Maret 2007 : 258-264

Riordan, Jan. 2010. Anatomy and Physiology of Lactation. Dalam : Riordan J, Wambach K (ed). Breastfeeding and Lactation 4th Ed. Sudbury : Jones and Barlett Publishers. h.91

Rodrigo GM, Rodriguez R, Quesada S. 2014. Hypothermia Risk Factors in The Very Low Weight Newborn and Associated Morbidity and Mortality in a Neonatal Care Unit. Journal of An Pediatric (Barc), 2014 March; 80(3) : 144150

Roesli, Utami. 2000. Mengenal ASI Eksklusif. Jakarta : Trubus Agriwidya. h.2-8

Roesli, Utami. 2008. Inisiasi Menyusu Dini Plus ASI Eksklusif. Jakarta : Pustaka Bunda. h.3-37

Rudolph AM, Hoffman JIE, Rudolph CD. 2006. Bayi Baru Lahir. Dalam : Phibbs RH (ed). Buku Ajar Pediatri Rudolph Edisi 20 Volume 1. Jakarta : EGC. h. $242-244$

Saleha, Siti. 2009. Asuhan Kebidanan pada Masa Nifas. Jakarta : Salemba Medika. h.54-56

Sugiyono. 2010. Statistika Untuk Penelitian. Bandung : Alfabeta. h.121-124

Sumirat FA, Sitaresmi MN, Ismail D. 2009. Pengaruh Pemberian ASI Terhadap Kenakalan pada Anak Sekolah Dasar di Yogyakarta. Jurnal Sari Pediatri Vol. 10, No. 6. April $2009: 362-366$
Suradi, Rulina. 2010. Pemeriksaan Fisis pada Bayi Baru Lahir. Dalam : Kosim MS, Yunanto A, Dewi R, dkk. (ed). Neonatologi. Jakarta : Badan Penerbit IDAI. h. $71-73$

Winberg J. 2005. Mother and Newborn Baby: Mutual Regulation of Physiology and Behavior-A Selective Review. Journal of Dev Psychobiol, 2005 November; 47(3) : 217229

World Health Organization. 2009. Pelayanan Kesehatan Anak di Rumah Sakit : Pedoman Bagi Rumah Sakit Rujukan Tingkat Pertama di Kabupaten/Kota. Jakarta : WHO Indonesia. h.50-51

World Health Organization. 2012. World Health Statistic 2012. Diakses tgl 9 Maret 2013. Diunduh dari URL: http:/ /www.who.int/healthinfo/ EN_WHS2012_Full.pdf

Yuliarti, Nurheti. 2010. Keajaiban ASI - Makanan Terbaik Untuk Kesehatan, Kecerdasan dan Kelincahan Si Kecil. Yogyakarta : CV Andi Offset. h.25-29

Yunanto, Ari. 2010. Termoregulasi. Dalam : Kosim MS, Yunanto A, Dewi R, dkk. (ed). Neonatologi. Jakarta : Badan Penerbit IDAI. h.89-97 